\title{
HOMICÍDIOS NAS CIDADES MÉDIAS DA BAHIA: OS NÚMEROS DA VIOLÊNCIA NOS CENTROS REGIONAIS DO INTERIOR BAIANO
}

\author{
Cícero Harisson Souza \\ Universidade Federal de Pernambuco, Programa de Pós-Graduação em Geografia, Recife, PE, Brasil \\ harisson.feeling@gmail.com
}

\begin{abstract}
RESUMO
A Bahia vem apresentando números que indicam crescimento em suas taxas de homicídios. Desde os anos 2000 o Estado construiu uma trajetória de superação dos índices nacionais que abordam a violência, sobretudo os homicídios. Este trabalho tem como objetivo elaborar um panorama em centros interioranos, partindo das escalas nacional e estadual, tendo como premissas reflexões, dados comparativos em série histórica e a criticidade quanto à eficácia das políticas públicas adotadas. A dinâmica dos indicadores possibilitou analisar o tema na escala intermunicipal, cujas cidades foram selecionadas a partir da Divisão Urbano Regional realizada pelo IBGE em 2013. O critério adotado foi o de centralidade em suas respectivas regiões. Num esforço de síntese, podese afirmar que as cidades deste trabalho se inserem acima da média brasileira nos dados que compõem indicadores violentos, e expressam um quadro situacional de vulnerabilidade socioeconômica. Para a formulação de mudanças, o debate social é o canal mais apropriado. Reconhecer a complexidade da questão e expor para a sociedade formas de dialogar sobre o tema é uma iniciativa que pode reforçar a segurança e a pacificação dos conflitos violentos.
\end{abstract}

Palavras-chave: Rede Urbana. Criminalidade. Nordeste. Mortes violentas.

\section{HOMICIDES IN THE MEDIUM SIZE CITIES OF BAHIA: THE NUMBERS OF VIOLENCE IN THE REGIONAL CENTERS OF THE INLANDS}

\begin{abstract}
The State of Bahia has been presenting numbers that indicate growth in its homicide rates. Since the 2000s, the state has built a path of worsening national indexes that address violence, especially homicides. This work aims to elaborate a panorama in inland cities, starting from the national and state scales, having as premisses reflections, comparative data in a historical series and the criticity as to the effectiveness of the public policies adopted. The dynamics of the indicators made it possible to analyze the theme in the intermunicipal scale, whose cities were selected from the IBGE 2013 Urban-Regional Division. The criterion adopted was that of centrality in their respective regions. In a synthesis effort, it can be stated that the cities of this study are above the Brazilian average considering the data which compose violent indicators, and express a situational picture of socioeconomic vulnerability. For the formulation of changes, social debate is the most appropriate channel. Recognizing the complexity of the issue and exposing to society ways to dialogue on the issue is an initiative that can enhance security and pacification of violent conflicts.
\end{abstract}

Palavras-chave: Urban Network. Criminality. Northeast. Violent Death.

\section{INTRODUÇÃO}

O Atlas da Violência (2018) trouxe um mapeamento de mortes violentas nos municípios brasileiros com população superior aos 100 mil habitantes, o ano de referência é 2016. De acordo com a metodologia do estudo, os dados foram obtidos através do Sistema de Informação sobre Mortalidade do Ministério da Saúde (SIM/MS).

Em 2016 a maiores taxas de homicídio dos municípios estiveram com mais ênfase nas regiões Norte e Nordeste. O estudo tem como conceito de mortes violentas "a soma de agressões, intervenções legais e mortes com causa indeterminada, tomando como referência o município de residência da vítima" (ATLAS

$\begin{array}{llllll}\text { Caminhos de Geografia } & \text { Uberlândia } & \text { v. 20, n. } 72 & \text { Dez/2019 } & \text { p. } 472-486 & \text { Página } 472\end{array}$


DA VIOLÊNCIA, 2018). Em 2016, 10.274 mortes violentas não tiveram a causa esclarecida $(6,6 \%$ do total), o que pode gerar grandes diferenças na prevalência de homicídios no âmbito do município. Conforme estimativas de Cerqueira (2013), 73,9\% dessas mortes violentas com causa indeterminada eram, na verdade, agressões mal classificadas. Portanto, para evitar maiores distorções nas taxas de mortes violentas entre os municípios, o estudo agregou essa categoria ao que foi definido anteriormente como homicídios.

De acordo com Santos (2009), o contexto urbano apresenta muitos conflitos, distorções no campo social. "Nas cidades de médio porte, as pessoas assistem estarrecidas ao crescimento do índice de violência, paralelo ao surgimento de bolsões de pobreza, em que os integrantes podem estar à espreita nos locais de risco" (SANTOS, 2009, p. 238).

Para Santos (2009), a transformação da cidade globalizada a trouxe para um campo de conflito de interesses, dividindo-a em "fragmentos antagônicos". Os atores sociais, nela presente, não se sentem amparados pelas instituições. Desse modo, eles adotam medidas de sobrevivência para estarem inseridos nos padrões impostos pelo neoliberalismo. Os salários mal remunerados, desemprego, as formas desiguais de oportunidades, são alguns aspectos do empobrecimento de uma parcela considerável da cidade moderna. Tal aumento da pobreza "têm gerado muito dos crimes contra o patrimônio, tais como furtos, roubos e assaltos" (SANTOS, 2009, p. 240). Este cenário coloca em questão a efetividades das ações adotadas pela esfera pública.

\begin{abstract}
"Políticas de segurança pública efetivas são o conjunto de princípios, programas e ações de natureza intersetorial que garantem baixas taxas de crime e de sensação de insegurança e medo. Quando as expectativas futuras dos cidadãos se deterioram, quando o medo começa a imperar, deixa-se de confiar nas instituições do Estado, e as pessoas passam a abandonar o espaço público, segregam-se dentro de condomínios e compram armas de fogo. Como se sabe, o medo é um péssimo conselheiro". (ATLAS DA VIOLÊNCIA, 2018, p. 3)
\end{abstract}

Alguns elementos são cruciais para as políticas públicas terem efetividade: comprometimento político; mobilização e articulação de forças sociais; organização da gestão da segurança pública se apropriando do empirismo, método científico; medidas mais propícias ao controle de armas e munições; promover espaços que disseminem o diálogo sobre a violência; promover mudanças no modelo de polícia com visão estratégica do trabalho policial e de informações produzidas pela inteligência e investigação; e por último, estruturar uma política de prevenção social - dando acesso a boa educação e oportunidades no mercado de trabalho para os jovens (ATLAS DA VIOLÊNCIA, 2018). Todos os aspectos até então abordados, estão presentes nas cidades médias da Bahia. O estado possui uma rede urbana ampla, com uma diversidade de polos regionais. Este artigo utilizou o critério da Divisão Urbano Regional (IBGE, 2013) para compor os espaços a serem analisados. O objetivo foi mapear os dados que compõem indicadores violentos, e expressam um quadro situacional de vulnerabilidade socioeconômica no território baiano, a partir dos principais centros urbanos.

\title{
ESCOLHA DAS CIDADES
}

As cidades médias selecionadas para o recorte possuem funções de Capitais Regionais. O estudo do IBGE propõe um avanço sobre a temática de redes, em relação ao desempenho na influência das urbes em sua hinterlândia. O produto é a identificação de um município polo para cada região. "Todas as regiões identificadas são formadas a partir de uma cidade que comanda a sua região, estabelecendo relacionamentos entre agentes e empresas nos respectivos territórios" (IBGE, 2013, p.3)

A divisão regional realizada pelo IBGE (2013) possibilitou a formação de três níveis escalares de articulação urbana: Região Ampliada, Região Intermediária e Região Imediata. A Região Ampliada é composta por 14 regiões identificadas no Brasil que possuem o mérito de revelar no território nacional o protagonismo da geografia traçada pelos fluxos socioeconômicos no processo contínuo de estruturação do território nacional. A Região Intermediária é constituída por 161 regiões brasileiras identificadas que são resultado da subdivisão das regiões Ampliadas. Distinguem-se por possuir centros urbanos nos níveis de Capital regional, formando regiões com centralidades medianas no conjunto da classificação e com população e área de tamanhos que variam conforme a localização. A Região Imediata -é formada por482 regiões identificadas no país, que são regiões formadas em torno dos Centros sub-regionais, de atuação abaixo dos de Capital regional. A busca por essas localidades é pautada em atividades com demandas de amplitude mais restritas. É o espaço cotidiano da população com serviços mais corriqueiros. (IBGE, 2013).

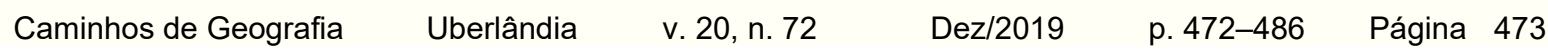


O estudo também possibilitou na construção das regiões geográficas estaduais, que consistem numa atualização das mesorregiões e microrregiões propostas pelo IBGE. As intermediárias desempenham a função de comando sobre suas áreas imediatas. A escolha das cidades que irão compor as séries históricas, no panorama da violência, são os principais centros das Regiões Intermediárias. Dentre elas foram selecionadas: Feira de Santana, Vitória da Conquista, Juazeiro, Illéus, Itabuna, Barreiras e Porto Seguro (esta última está inserida da Região Intermediária de llhéus-Itabuna, a cidade possui uma Região Imediata própria - categoria inferior às demais escolhidas. Contudo, a decisão de aderir Porto Seguro na análise, foi obtida a partir de aspectos que lhe são peculiares: principal destino turístico baiano no interior do estado, apresentar um cenário de crescimento nos indicadores de violência e ter uma infraestrutura socioeconômica que pode trazer números comparativos interessantes neste panorama). Todas com mais de cem mil residentes. Entende-se que a Região de Salvador tem protagonismo na temática, porém, este trabalho objetiva averiguar apenas as áreas interioranas do estado.

Após o detalhamento metodológico quanto a seleção dos locais de pesquisa, os números serão analisados em recortes temporais pós ano 2000. O marco da última década permitiu esboçar a trajetória dos dados sobre os homicídios. Na escala estadual, outras abordagens do tema (sistema prisional, população carcerária), serão contrapostas ao âmbito nacional.

\section{RESULTADOS E DISCUSSÕES}

O Atlas da Violência traz alguns indicadores-chave de abordagem econômica e social que compõem um retrato dos 309 municípios com população superior aos 100 mil habitantes. A tabela 1 mostra os dados das cidades baianas.

Conforme a tabela 1 a maior taxa de homicídio foi a de Porto Seguro 101,7\%o (extremo Sul). A menor taxa registrada foi em Juazeiro (extremo Norte) com $48,1 \%$, sendo esta cidade o principal núcleo urbano da divisa entre Bahia e Pernambuco.

Nos indicadores referentes ao trabalho e a renda, percebe-se que as cidades baianas estão abaixo da média nacional. Feira de Santana e Barreiras tiveram o maior valor de renda per capita no estrato populacional dos $20 \%$ mais pobres, ambas acima de 160 reais. Juazeiro apresentou o menor valor com 131 reais. O percentual de jovens que não trabalham, nem estudam e estão em condições de vulnerabilidade, também estava acima da média dos demais municípios do país. Em llhéus e Juazeiro este índice ultrapassou a marca dos $17 \%$.

Nas variáveis de pobreza (\% de crianças pobres e de vulneráveis), os dados mostram que este é um fator que requer aplicações medidas mais ativas na redução das desigualdades, todas as cidades possuem percentuais bem acima do parâmetro nacional. Em ambas as situações, Juazeiro, llhéus e Porto Seguro se destacaram negativamente. Quanto a precariedade dos domicílios (sem água encanada e saneamento básico adequados), somente Itabuna teve percentual menor que a média brasileira. São $3,7 \%$ dos habitantes vivendo nesta condição no município sul baiano, e 3,8\% da média.

Por fim, a gravidez na adolescência, sendo considerada precoce, foi mais evidente em llhéus e Porto Seguro. As duas cidades superaram o dobro da média, ultrapassando a marca de $5 \%$ contra $2,5 \%$ do recorte nacional.

Estes dados são importantes para leituras da violência no país, pois, "analisando a correlação entre as condições de desenvolvimento humano e as taxas de mortes violentas, em geral, nos municípios com melhores níveis de desenvolvimento humano a taxa de homicídio tende a ser menor" (ATLAS DA VIOLÊNCIA, 2018, p.11). Em 2016, ano de referência dos dados sobre a violência, $50 \%$ das mortes violentas aconteceram em 123 municípios. Muitos deles em regiões de alta vulnerabilidade a pobreza. 
Tabela 1. Indicadores-chave das cidades selecionadas

\begin{tabular}{|c|c|c|c|c|c|c|c|c|}
\hline Indicador & $\begin{array}{l}\text { Feira de } \\
\text { Santana }\end{array}$ & $\begin{array}{l}\text { Vitória da } \\
\text { Conquista }\end{array}$ & Juazeiro & Itabuna & Ilhéus & Barreiras & Porto Seguro & $\begin{array}{c}\text { Média } \\
\text { (Brasil) } \\
\text { (1) }\end{array}$ \\
\hline População (2016) & $622 \mathrm{mil}$ & $346 \mathrm{mil}$ & $220 \mathrm{mil}$ & 220 mil & $178 \mathrm{mil}$ & $155 \mathrm{mil}$ & $147 \mathrm{mil}$ & $375 \mathrm{mil}$ \\
\hline Taxa de Homicídios (2016) & 85,1 & 68,5 & 48,1 & 69,9 & 56,1 & 64,9 & 101,7 & 38,6 \\
\hline $\begin{array}{l}\text { Renda per Capita dos } 20 \% \text { mais pobres } \\
\text { em } \mathbf{R} \$(2010)\end{array}$ & 164,80 & 151,70 & 131,00 & 155,50 & 143,20 & 162,90 & 144,10 & 250,14 \\
\hline$\%$ de crianças pobres $(2010)$ & 26,4 & 30,2 & 32,4 & 30,0 & 31,7 & 24,6 & 31,4 & 16,4 \\
\hline $\begin{array}{l}\text { \% de crianças vulneráveis a pobreza } \\
\qquad(2010)\end{array}$ & 56,0 & 58,8 & 64,8 & 58,2 & 61,6 & 55,6 & 63,3 & 39,0 \\
\hline $\begin{array}{l}\text { \% de pessoas em domicílios precários }{ }^{(2)} \\
\qquad(2010)\end{array}$ & 6,1 & 6,3 & 5,3 & 3,7 & 8,5 & 4,0 & 7,8 & 3,8 \\
\hline $\begin{array}{c}\% \text { de mulheres de } 10 \text { a } 17 \text { anos que } \\
\text { tiveram filhos } 2010\end{array}$ & 2,9 & 3,0 & 4,1 & 3,5 & 5,7 & 3,7 & 5,0 & 2,5 \\
\hline $\begin{array}{c}\text { \% de jovens nem-nem vulneráveis a } \\
\text { pobreza }{ }^{(3)}(2010)\end{array}$ & 11,6 & 12,0 & 17,2 & 15,4 & 17,6 & 15,0 & 14,9 & 9,0 \\
\hline
\end{tabular}

(1) Média dos Municípios brasileiros com mais de 100 mil habitantes; (2) Domicílios sem água encanada e sem esgotamento sanitário; (3) Pessoas de 15-24 anos que nem trabalham e nem estudam

Fonte: Atlas da Violência, 2018 a partir Diest/lpea e FBSP

\begin{tabular}{llllll}
\hline Caminhos de Geografia & Uberlândia & v. 20, n. 72 & Dez/2019 & p. 472-486 & Página
\end{tabular}




\title{
OCUPAÇÃO, RENDA E DESIGUALDADE
}

O desemprego e a pobreza são elementos que, a partir das contradições da vida urbana contemporânea, acentuam as desigualdades e estimulam a violência. "Os baixos salários e o desemprego, que causam o empobrecimento da classe média e o aumento do número de miseráveis (bolsões de pobreza), têm gerado muito dos crimes contra o patrimônio, tais como furtos, roubos e assaltos". (PEDRAZZINI, 2006 apud SANTOS, 2009, p. 241)

$\mathrm{Na}$ tabela 2 foram consideradas as variáveis de ocupação - percentual da população ocupada em atividade com remuneração; salário médio mensal - quantidade de salários mínimos; as respectivas posições no ranking nacional e o saldo de empregos no ano de referência, 2016.

Tabela 2 - Trabalho e Rendimento nas cidades selecionadas (2016)

\begin{tabular}{cccccc}
\hline Município & $\begin{array}{c}\text { Pessoal } \\
\text { ocupado } \\
\text { (\%) em } \\
\mathbf{2 0 1 6}\end{array}$ & $\begin{array}{c}\text { Ranking } \\
\text { Brasil }\end{array}$ & $\begin{array}{c}\text { Salário Médio } \\
\text { Mensal } \\
\text { (SM) em 2016 }\end{array}$ & $\begin{array}{c}\text { Ranking } \\
\text { Brasil }\end{array}$ & $\begin{array}{c}\text { Saldo de } \\
\text { Emprego } \\
\mathbf{2 0 1 6}\end{array}$ \\
\hline Vitória da Conquista & 21,6 & $1094 / 5570$ & 2,0 & $1807 / 5570$ & -1040 \\
Porto Seguro & 21,3 & $1133 / 5570$ & 1,8 & $2836 / 5570$ & +70 \\
Feira de Santana & 21,2 & $1136 / 5570$ & 2,0 & $1807 / 5570$ & -5853 \\
Itabuna & 20,8 & $1187 / 5570$ & 1,9 & $2309 / 5570$ & +179 \\
Ilhéus & 18,9 & $1409 / 5570$ & 2,5 & $502 / 5570$ & -1051 \\
Barreiras & 18,2 & $1494 / 5570$ & 2,0 & $1368 / 5570$ & -1331 \\
Juazeiro & 16,7 & $1713 / 5570$ & 2,0 & $1807 / 5570$ & +1.795 \\
\hline
\end{tabular}

Fonte: IBGE, 2016. Ministério da Economia, 2016.

Sobre a população ocupada, no comparativo nacional as cidades baianas se situaram em colocações mais altas, todas acima do milésimo patamar. No estado, os seis centros ficaram entre os trinta primeiros lugares. No cenário nacional os percentuais são baixos quando inserimos o ranking: Vitória da Conquista com $21,6 \%$ e Juazeiro com $16,7 \%$ são os extremos.

Em relação ao salário médio mensal, os valores tiveram oscilação menor entre os centros escolhidos. Em Ilhéus, a média salarial mensal foi de 2,5 salários mínimos, o maior da tabela 2. Por outro lado, Porto Seguro apresentou a menor média com 1,8 salários mínimos. As cidades de Feira de Santana, Vitória da Conquista, Juazeiro e Barreiras, obtiveram 2 salários mínimos como rendimento médio. No Brasil, o desempenho das urbes quanto ao rendimento médio foi pior do que a variável de ocupação.

No ano de 2016 a crise nacional afetou os municípios com o desemprego. Apenas Juazeiro teve um expressivo saldo positivo, com 1.793 vagas formais naquele ano. Porto Seguro e Itabuna também fecharam positivamente com 70 e 173 vagas, respectivamente. As demais cidades tiveram saldo negativo, sendo Feira de Santana com o maior número de postos de trabalhos fechados, superior a $-5,8$ mil empregos.

Para Carvalho et al (2017) a falta de emprego associada a precarização dos salários causa instabilidade social.

\begin{abstract}
"Em uma esfera macroeconômica maior taxa de desocupação ocasiona aumentos na pobreza, maiores gastos governamentais, além de elevação no índice de criminalidade, visto que de acordo com a abordagem da escolha racional, um indivíduo desempregado encontra como opção o ato ilícito, assumindo o risco inerente ao ato criminoso, dependendo principalmente da probabilidade de sucesso ou não na atividade." (ARAÚJO e ANTIGO, 2015 apud CARVALHO et al., 2017, p.1806).
\end{abstract}

A exposição destes autores argumenta que a questão da criminalidade é interdisciplinar, unindo a esfera social, jurídica, a segurança pública e a economia. Visto que a crise econômica acompanha o crescimento dos indicadores de violência. É preciso ponderar também que, parte do aumento dos números em alguns estados decorreu da migração de facções e do aumento do tráfico de drogas (GENNARI, 2019). O Nordeste experimentou uma redução das desigualdades na década 2000-2010, porém a criminalidade aumentou. Este é um tema que requer uma investigação mais aprofundada, um campo fértil para outros trabalhos.

$\begin{array}{llllll}\text { Caminhos de Geografia } & \text { Uberlândia } & \text { v. } 20, \text { n. } 72 & \text { Dez/2019 } & \text { p. 472-486 } & \text { Página } 476\end{array}$


A tabela 3 agrupa indicadores de desigualdade e desenvolvimento, ambos contribuem na leitura dos conflitos urbanos e sociais.

Tabela 3 - Indicadores de desigualdade e desenvolvimento nas cidades selecionadas

\begin{tabular}{|c|c|c|c|c|c|c|}
\hline Município & IDH & Classificação & $\begin{array}{c}\text { IDH } \\
\text { Renda }\end{array}$ & $\begin{array}{c}\text { IDH } \\
\text { Educação }\end{array}$ & $\begin{array}{c}\text { IDH } \\
\text { Longevidade }\end{array}$ & $\begin{array}{l}\text { Indice } \\
\text { de Gini }\end{array}$ \\
\hline Barreiras & 0,721 & Alto & 0,695 & 0,668 & 0,807 & 0,56 \\
\hline Feira de Santana & 0,712 & Alto & 0,710 & 0,619 & 0,820 & 0,60 \\
\hline Itabuna & 0,712 & Alto & 0,695 & 0,643 & 0,807 & 0,56 \\
\hline Ilhéus & 0,690 & Médio & 0,688 & 0,590 & 0,808 & 0,58 \\
\hline $\begin{array}{l}\text { Vitória da } \\
\text { Conquista }\end{array}$ & 0,678 & Médio & 0,681 & 0,581 & 0,788 & 0,55 \\
\hline Juazeiro & 0,677 & Médio & 0,657 & 0,594 & 0,796 & 0,56 \\
\hline Porto Seguro & 0,676 & Médio & 0,673 & 0,572 & 0,801 & 0,56 \\
\hline Bahia & 0,660 & Médio & 0,663 & 0,555 & 0,783 & 0,62 \\
\hline Brasil & 0,727 & Alto & 0,739 & 0,637 & 0,816 & 0,60 \\
\hline
\end{tabular}

Fonte: PNUD, 2013.

O Índice de Desenvolvimento Humano (IDH) de Barreiras, Feira de Santana e Itabuna foram classificados como "alto", os demais como "médio". Decompondo o valor pelos demais indicadores, na renda apenas Feira de Santana continuou no patamar "alto", as outras cidades obtiveram índice "médio". Em educação o maior valor foi feirense como 0,668 sendo "médio". A longevidade foi a esfera em que os municípios se saíram melhor: Feira de Santana com 0,820 e Vitória da Conquista com 0,788 foram os extremos mais alto e mais baixo, respectivamente. $\mathrm{O}$ estado ficou abaixo da média nacional em todos os indicadores que compõem o IDH.

O Índice de Gini foi o instrumento utilizado para a abordagem da desigualdade (mais próximo de 1,00 maior desigualdade; mais próximo de 0,00 menor desigualdade). A concentração de renda foi maior na Bahia $(0,62)$ do que no Brasil $(0,60)$. Contudo, as cidades selecionadas eram menos desiguais do que o país e a Bahia, excetuando Feira de Santana $(0,60)$. A cidade de Vitória da Conquista foi a que apresentou menor concentração de renda com 0,55 . Todas as escalas apresentaram coeficiente de Gini alto para os parâmetros mundiais.

\begin{abstract}
"No Brasil, a desigualdade social é recorrentemente citada como uma das principais causas da violência e da criminalidade, tanto em estudos acadêmicos quanto em debates públicos. Para Pinheiro (1997), a desigualdade, a pobreza e a exclusão social, resultantes das políticas neoliberais seriam propulsoras da violência urbana. Além disto, o alto índice de jovens e pobres envolvidos com o crime demonstra a relação entre pobreza e violência, para eles a criminalidade torna-se um canal mais rápido de mobilidade social". (SCHABBACH, 2014, p.10)
\end{abstract}

Segundo Schabbach (2014) em áreas mais pobres com urbanização deficitária, baixos níveis de satisfação das necessidades, renda precária e analfabetismo, prevaleceram as altas taxas de homicídios. Em contraponto, regiões mais nobres em municípios mais ricos, que geram mais riquezas os crimes mais frequentes são aqueles contra o patrimônio público.

\begin{abstract}
"Para Cano e Santos (2001), a maior incidência da violência letal em bairros pobres revela que a renda é um fator de proteção contra a violência letal, pois os indivíduos com renda alta são menos propensos a serem mortos do que os de renda baixa. A renda elevada permite maiores gastos com serviços e equipamentos de segurança e a moradia em zonas com maior qualidade de vida e mais policiadas." (SCHABBACH, 2014, p.11).
\end{abstract}

\title{
ANÁLISES EM SÉRIE HISTÓRICA: A TRAJETÓRIA DOS NÚMEROS NA ÚLTIMA DÉCADA
}

Nesta etapa do trabalho as discussões serão apresentadas a partir de tabelas acompanhadas de figuras, sobre duas variáveis: número total de mortes por violência e a taxa de homicídios. O recorte escolhido entre 2000 e 2010 tem como foco a análise da década. A tabela 4, juntamente com a figura 1, apresenta a dinâmica numérica quanto ao valor absoluto de homicídios registrados na última década (entre os anos 2000 e 2010).

\begin{tabular}{llllll}
\hline Caminhos de Geografia & Uberlândia & v. 20, n. 72 & Dez/2019 & p. 472-486 & Página 477
\end{tabular}


Tabela 4 - Série histórica do número de óbitos na última década (2000-2010)

\begin{tabular}{cccccccccccc}
\hline Município & $\mathbf{2 0 0 0}$ & $\mathbf{2 0 0 1}$ & $\mathbf{2 0 0 2}$ & $\mathbf{2 0 0 3}$ & $\mathbf{2 0 0 4}$ & $\mathbf{2 0 0 5}$ & $\mathbf{2 0 0 6}$ & $\mathbf{2 0 0 7}$ & $\mathbf{2 0 0 8}$ & $\mathbf{2 0 0 9}$ & $\mathbf{2 0 1 0}$ \\
\hline Feira de Santana & 84 & 72 & 97 & 41 & 41 & 49 & 199 & 194 & 241 & 286 & 342 \\
Vitória da Conquista & 53 & 75 & 72 & 111 & 115 & 112 & 102 & 128 & 149 & 196 & 267 \\
Juazeiro & 70 & 147 & 73 & 133 & 122 & 127 & 131 & 111 & 110 & 87 & 93 \\
Itabuna & 77 & 77 & 92 & 100 & 118 & 156 & 143 & 174 & 208 & 232 & 209 \\
$\quad$ Ilhéus & 42 & 49 & 40 & 51 & 63 & 99 & 116 & 106 & 110 & 135 & 121 \\
Barreiras (1) & $\mathrm{S} / \mathrm{D}$ & $\mathrm{S} / \mathrm{D}$ & $\mathrm{S} / \mathrm{D}$ & $\mathrm{S} / \mathrm{D}$ & $\mathrm{S} / \mathrm{D}$ & $\mathrm{S} / \mathrm{D}$ & $\mathrm{S} / \mathrm{D}$ & $\mathrm{S} / \mathrm{D}$ & $\mathrm{S} / \mathrm{D}$ & $\mathrm{S} / \mathrm{D}$ & $\mathrm{S} / \mathrm{D}$ \\
Porto Seguro & 25 & 22 & 32 & 37 & 53 & 92 & 123 & $\mathbf{7 1}$ & 114 & 128 & 160 \\
\hline \hline Bahia & $\mathbf{1 . 2 2 3}$ & $\mathbf{1 . 5 7 9}$ & $\mathbf{1 . 7 3 5}$ & $\mathbf{2 . 1 5 5}$ & $\mathbf{2 . 2 5 5}$ & $\mathbf{2 . 8 2 3}$ & $\mathbf{3 . 2 7 8}$ & $\mathbf{3 . 6 1 4}$ & $\mathbf{4 . 7 6 5}$ & $\mathbf{5 . 3 8 3}$ & $\mathbf{5 . 7 6 3}$ \\
\% Cidades / UF & $\mathbf{2 8 , 7 \%}$ & $\mathbf{2 7 , 9 \%}$ & $\mathbf{2 3 , 4} \%$ & $\mathbf{2 1 , 9 \%}$ & $\mathbf{2 2 , 7 \%}$ & $\mathbf{2 2 , 5 \%}$ & $\mathbf{2 4 , 8 \%}$ & $\mathbf{2 1 , 7 \%}$ & $\mathbf{1 9 , 5 \%}$ & $\mathbf{1 9 , 7 \%}$ & $\mathbf{2 0 , 7 \%}$ \\
\hline
\end{tabular}

(1) SD (Sem dados) - Os dados referentes ao município não estavam disponíveis na fonte, sem frequência de série histórica. Para não gerar distorções, Barreiras não fará parte desta análise.

Fonte: Deepask, 2010

\begin{tabular}{llllll}
\hline Caminhos de Geografia & Uberlândia & v. 20, n. 72 & Dez/2019 & p. 472-486 & Página 478
\end{tabular}


Figura 1 - Número de óbitos na última década (2000-2010)

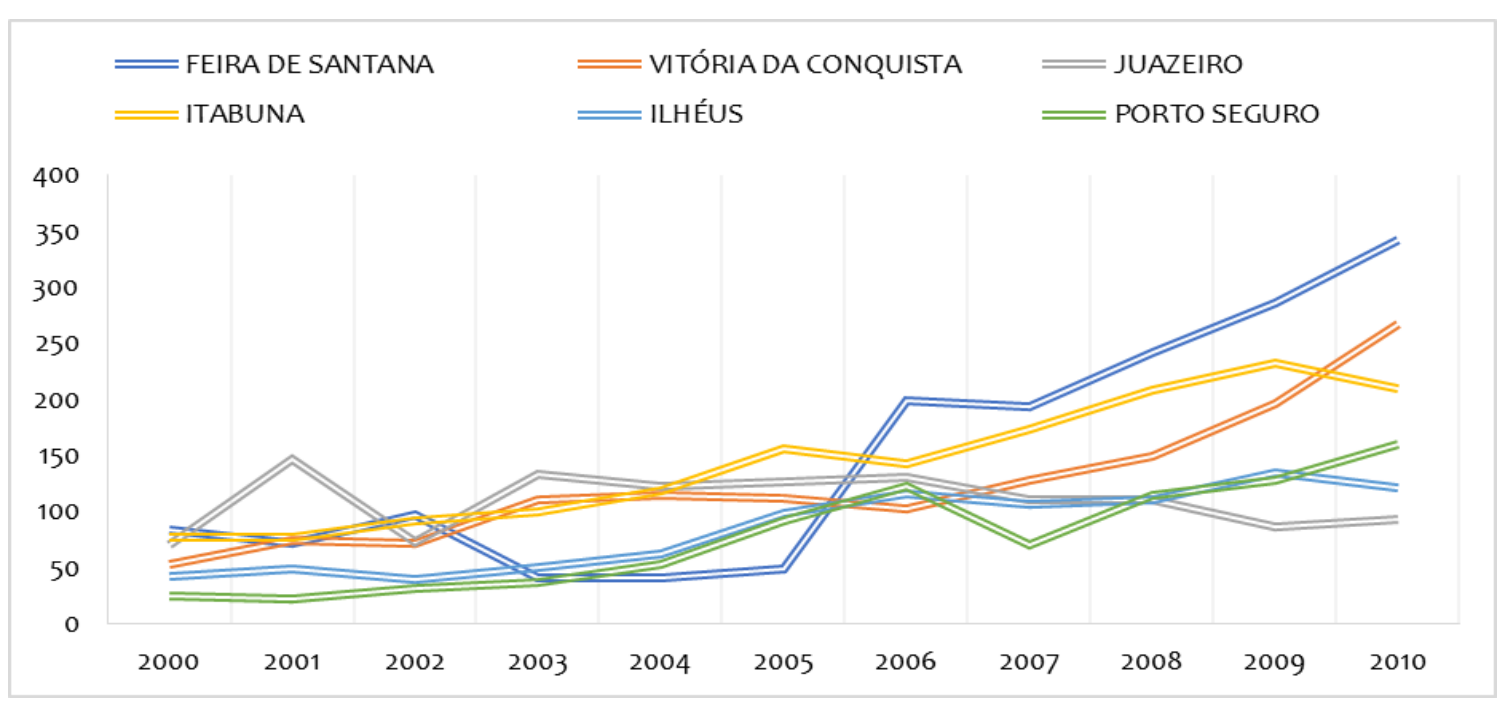

Fonte: Deepask, 2010.

Destaque nos anos iniciais, Juazeiro que ocupava as primeiras colocações passou a ter queda no total de óbitos. Em 2000 a cidade do norte baiano obteve 70 mortes, no ano seguinte em 2001 atingiu seu pico com 147. Finalizou o ano de 2010 com 93 homicídios.

Itabuna, no sul do estado, também mostrou valores expressivos no recorte temporal. Dividiu com Juazeiro o posto de cidade mais violenta do quadro, porém sua participação caiu em relação a Feira de Santana e Vitória da Conquista (ao final da década).

A Bahia registrou 1.223 óbitos em 2000 e quadruplicou o total de casos com 5.763 em 2010. Embora as cidades selecionadas tenham aumentado seus registros, no estado esse crescimento foi maior. Enquanto no primeiro ano do recorte os municípios da tabela possuíam uma participação relativa de $28,7 \%$ do total de casos da Bahia, em 2010 essa participação caiu para 20,7\%, decorrente dos expressivos dados de Salvador e sua Região Metropolitana (315 homicídios em 2000; 1.847 em 2010). No cenário nacional o Brasil atingiu 45.360 mortes em 2000, finalizando o ano de 2010 com 52.260 homicídios. Um aumento de $15 \%$ no intervalo de dez anos.

A tabela 5 , acompanhada da figura 2 , traz os dados referentes as taxas de homicídio. 
Tabela 5 - Série histórica da taxa de homicídios (\%) na última década (2000-2010)

\begin{tabular}{cccccccccccc}
\hline Município & $\mathbf{2 0 0 0}$ & $\mathbf{2 0 0 1}$ & $\mathbf{2 0 0 2}$ & $\mathbf{2 0 0 3}$ & $\mathbf{2 0 0 4}$ & $\mathbf{2 0 0 5}$ & $\mathbf{2 0 0 6}$ & $\mathbf{2 0 0 7}$ & $\mathbf{2 0 0 8}$ & $\mathbf{2 0 0 9}$ & $\mathbf{2 0 1 0}$ \\
\hline Feira de Santana & 17,4 & 14,7 & 19,5 & 8,1 & 8,0 & 9,3 & 37,1 & 35,6 & 41,2 & 48,4 & 61,4 \\
Vitória da Conquista & 20,1 & 28,1 & 26,6 & 40,5 & 41,4 & 39,1 & 35,1 & 43,5 & 47,4 & 61,4 & 87,0 \\
Juazeiro & 40,1 & 81,8 & 39,6 & 70,5 & 63,1 & 62,4 & 62,8 & 52,0 & 46,3 & 35,6 & 47,0 \\
Itabuna & 39,1 & 38,9 & 46,2 & 50,0 & 58,6 & 76,5 & 69,7 & 84,3 & 98,0 & 108,5 & 102,1 \\
Ilhéus & 18,9 & 22,1 & 18,0 & 23,0 & 28,4 & 44,7 & 52,5 & 48,0 & 50,1 & 61,5 & 65,6 \\
Barreiras (1) & $S / D$ & $S / D$ & $S / D$ & $S / D$ & $S / D$ & $S / D$ & $S / D$ & $S / D$ & $S / D$ & $S / D$ & $S / D$ \\
Porto Seguro & 26,1 & 21,3 & 29,4 & 32,3 & 44,0 & 68,6 & 87,3 & 48,1 & 94,6 & 104,1 & 126,0 \\
Bahia & $\mathbf{9 , 4}$ & $\mathbf{1 1 , 9}$ & $\mathbf{1 3 , 0}$ & $\mathbf{1 6 , 0}$ & $\mathbf{1 6 , 6}$ & $\mathbf{2 0 , 4}$ & $\mathbf{2 3 , 5}$ & $\mathbf{2 5 , 7}$ & $\mathbf{3 2 , 9}$ & $\mathbf{3 6 , 8}$ & $\mathbf{4 1 , 1}$ \\
Brasil & $\mathbf{2 6 , 7}$ & $\mathbf{2 7 , 8}$ & $\mathbf{2 8 , 5}$ & $\mathbf{2 8 , 9}$ & $\mathbf{2 7 , 0}$ & $\mathbf{2 5 , 8}$ & $\mathbf{2 6 , 3}$ & $\mathbf{2 5 , 2}$ & $\mathbf{2 6 , 4}$ & $\mathbf{2 6 , 9}$ & $\mathbf{2 7 , 4}$
\end{tabular}

(1) SD (Sem dados) - Os dados referentes ao município não estavam disponíveis na fonte, sem frequência de série histórica. Para não gerar distorções, Barreiras não fará parte desta análise.

Fonte: Deepask, 2010.

\begin{tabular}{llllll}
\hline Caminhos de Geografia & Uberlândia & v. 20, n. 72 & Dez/2019 & p. 472-486 & Página 480
\end{tabular}


Figura 2 - Taxa de homicídios na última década (2000-2010)

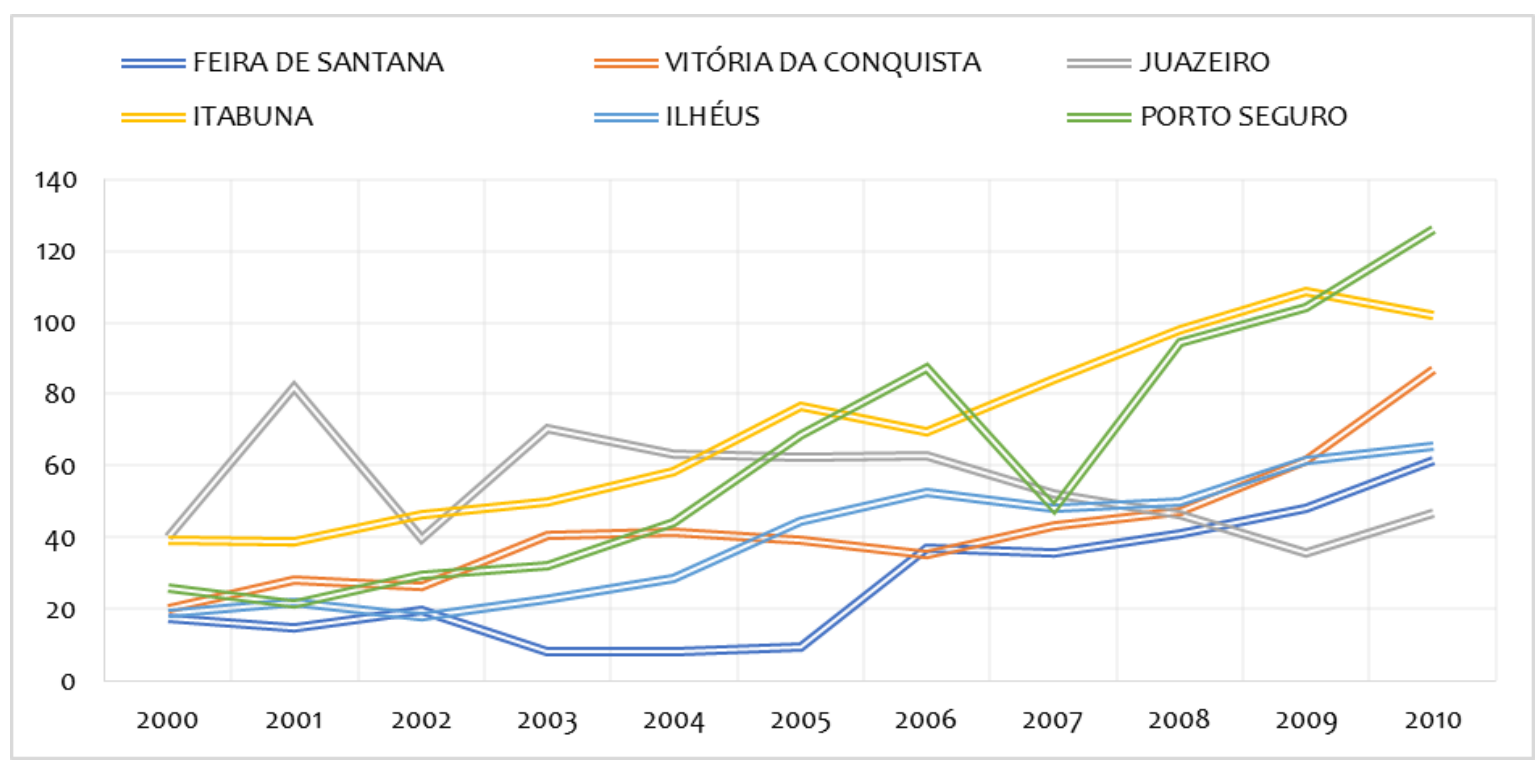

Fonte: Deepask, 2010.

De modo proporcional, por terem tamanhos populacionais diferentes, o quadro de análise leva os números para suas devidas proporções. Juazeiro também obteve o mesmo desempenho no parâmetro proporcional, a taxa do município era a mais elevada em 2000, porém em 2010 foi a menor registrada. Itabuna continuou tendo destaque no cenário, no último ano sua taxa foi superada por Porto Seguro. A cidade do extremo sul baiano tem o menor número populacional, contudo, sua taxa de homicídios mais do que quadruplicou. No ano final todas as cidades selecionadas ficaram acima da taxa estadual de 41,1 óbitos por 100 mil habitantes.

No comparativo com o país, percebe-se que a Bahia tinha uma taxa muito inferior à média nacional $(9,4 \%$ na Bahia; 26,7 no Brasil \%o). Porém, na trajetória da década, o estado superou consideravelmente a taxa brasileira. O Brasil apresentou números constantes na tabela, oscilando entre 25,2 e 28,9 mortes por 100 mil habitantes. O momento da ultrapassagem ocorreu em 2007 e a partir dele, a taxa cresceu de forma mais intensa até o patamar final, conforme mostra a figura 3 e a tabela 6 .

Figura 3 - Comparativo das Taxas de Homicídio (\%) Bahia x Brasil (2000-2010)

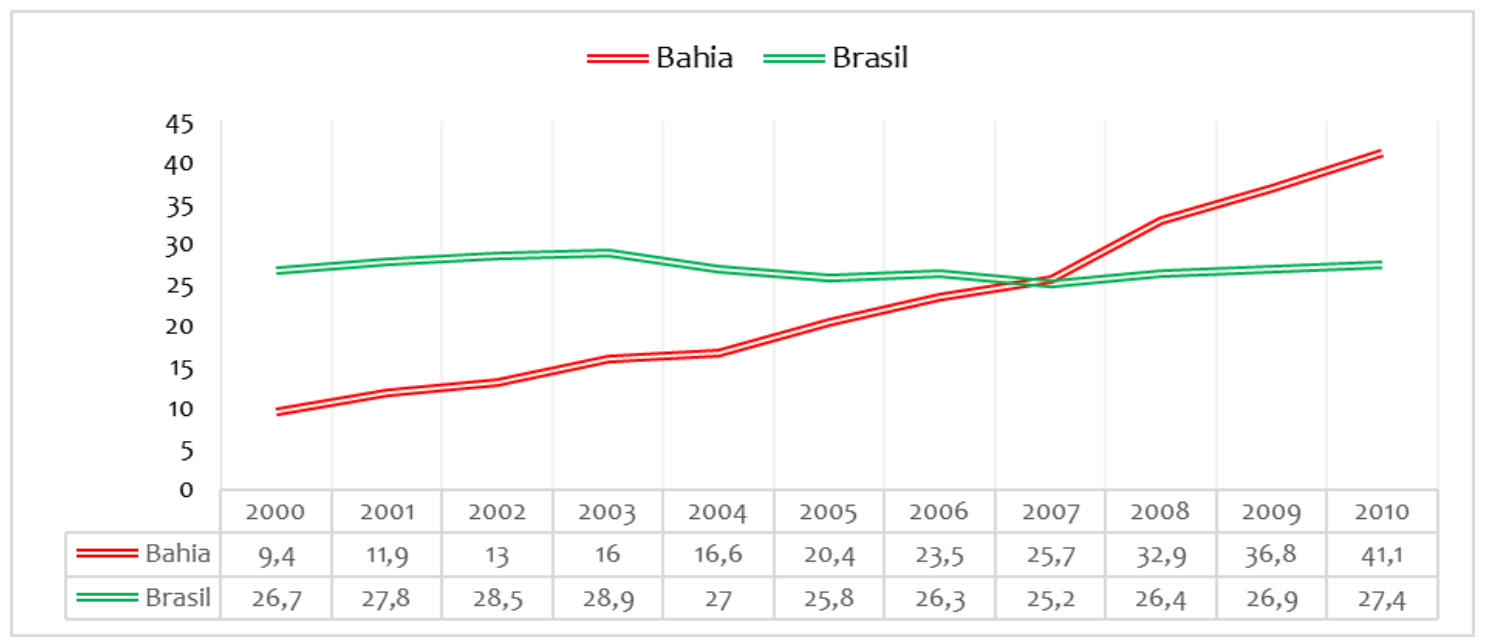

Fonte: Deepask, 2010.

$\begin{array}{llllll}\text { Caminhos de Geografia } & \text { Uberlândia } & \text { v. } 20, \text { n. } 72 & \text { Dez/2019 } & \text { p. 472-486 } & \text { Página } 481\end{array}$


Tabela 6 - Série histórica do número de óbitos na última década por COR (2000-2010)

\begin{tabular}{|c|c|c|c|c|c|c|c|c|c|c|c|c|}
\hline \multirow{2}{*}{$\begin{array}{c}\text { Ano } \\
\text { Município }\end{array}$} & \multicolumn{4}{|c|}{2000} & \multicolumn{4}{|c|}{2005} & \multicolumn{4}{|c|}{2010} \\
\hline & B & $\mathrm{Pa}$ & $\operatorname{Pr}$ & SE & B & $\mathrm{Pa}$ & $\operatorname{Pr}$ & SE & B & $\mathrm{Pa}$ & $\operatorname{Pr}$ & SE \\
\hline Feira de Santana & 7 & 54 & 9 & 14 & 2 & 37 & 8 & 2 & 4 & 219 & 76 & 38 \\
\hline Vitória da Conquista & 10 & 25 & 11 & 7 & 8 & 78 & 13 & 13 & 18 & 203 & 35 & 11 \\
\hline Juazeiro & 6 & 30 & 3 & 31 & 26 & 94 & 5 & 2 & 13 & 69 & 9 & 2 \\
\hline Itabuna & 3 & 27 & 9 & 38 & 10 & 119 & 19 & 8 & 6 & 177 & 22 & 4 \\
\hline Ilhéus & 1 & 18 & 6 & 17 & 6 & 76 & 15 & 2 & 0 & 110 & 9 & 2 \\
\hline Barreiras ${ }^{(1)}$ & $S / D$ & $S / D$ & $S / D$ & $S / D$ & $S / D$ & $S / D$ & $S / D$ & $S / D$ & $S / D$ & $S / D$ & $S / D$ & $S / D$ \\
\hline Porto Seguro & 5 & 17 & 3 & 0 & 5 & 70 & 7 & 9 & 9 & 129 & 12 & 10 \\
\hline TOTAL Cidades & 32 & 171 & 41 & 107 & 57 & 474 & 67 & 36 & 50 & 907 & 163 & 67 \\
\hline TOTAL Bahia & 92 & 744 & 133 & 252 & 168 & 2.101 & 232 & 319 & 361 & 4.295 & 774 & 320 \\
\hline
\end{tabular}

Legenda: B (Branca); Pa (Parda); Pr (Preta); SE (Sem Especificação)

(1) SD (Sem dados) - Os dados referentes ao município não estavam disponíveis na fonte, sem frequência de série histórica. Para não gerar distorções, Barreiras não fará parte desta análise.

Fonte: Deepask, 2010.

\begin{tabular}{llllll}
\hline Caminhos de Geografia & Uberlândia & v. 20, n. 72 & Dez/2019 & p. 472-486 & Página 482
\end{tabular}


Considerar a variável COR, dentre o quadro de violência possibilita identificar quais grupos estariam mais suscetíveis. Na tabela 6 foram estabelecidos três anos dentro da década passada. Na tabela 6 não fizeram parte da análise as categorias: amarela e indígena. Ambos os grupos tinham números muito pequenos de casos de homicídios, em alguns recortes eles não pontuavam. Foi decidido que não seriam inseridos neste quadro.

Em 2000, 2005 e 2010, pardos e pretos foram os que tiveram maior número de vítimas, respectivamente. Somados os casos dessas duas cores nas cidades selecionadas: no primeiro ano foram 212 óbitos; 541 no ano intermediário; e 1.070 no final da década. Entre 2000 e 2010 os homicídios destes dois grupos quintuplicou. No estado a situação se repete, os pardos e os pretos foram os que mais morreram. No último ano da tabela 6, a soma dos dois grupos correspondeu por $87,9 \%$ do total de homicídios registrados na Bahia ${ }^{2}$. Vale destacar que no Censo IBGE 2010, a população da Bahia (14.016.906) subdividida por cor era: Pardos (59,16\%); Brancos (22,19\%); Pretos $(17,10)$; outras e sem declaração $(1,55 \%)$.

É consenso nos estudos que envolvem casos de violência, que ela se manifesta de forma diferenciada sobre determinados grupos: cor, classe social, gênero, etc. A desigualdades é um dos fatores mais preponderantes. Outros trabalhos desenvolvidos na Bahia, mostram que a questão da cor coloca pretos e pardos em camadas sociais mais vulneráveis. Mesmo com o processo de industrialização e consequentemente de urbanização, não alterou a inclusão dos negros no mercado de trabalho (NORONHA et al, 1999, p. 275).

\section{BREVE EXPOSIÇÃO SOBRE O ENCARCERAMENTO NO BRASIL E NA BAHIA}

A limitação desta etapa foi a dificuldade de se obter os dados apresentados na escala municipal, notadamente das cidades selecionadas do trabalho. Por entender que o sistema de encarceramento e seus aspectos quantitativos são proeminentes na violência, foi elaborada uma breve explanação com o objetivo de situar o leitor, a respeito de alguns números do cenário carcerário no país e no estado.

O Conselho Nacional de Justiça (CNJ) através do Banco Nacional de Monitoramento de Prisões (BNMP) divulgou em agosto 2018, estatísticas referentes ao sistema e a população carcerária no país. Dentre os tipos penais mais recorrentes imputados às pessoas privadas de liberdade, o homicídio era a terceira tipificação penal com maior frequência - eram $11,3 \%$ dos casos, atrás apenas dos tipos roubos e tráfico de drogas com 27,6\% e 24,7\%, respectivamente (BNMP, 2018, p. 47). Nas notas metodológicas foi colocado que apenas parte das pessoas encarceradas responde a processo de conhecimento ou de execução em que se lhe imputa um único tipo penal, havendo uma diversidade de presos com múltiplas imputações. Sendo assim "a distribuição percentual dos tipos penais apresentadas se dá entre o conjunto total de imputações registrados nos documentos relativos a todas as pessoas privadas de liberdade cadastradas no sistema" (BNMP, 2018, p. 47).

A síntese do perfil das pessoas privadas de liberdade no Brasil, está apresentada na tabela 6 . Ela aponta quais são os grupos que se destacam dentro de suas respectivas variáveis. Cerca de 1/3 dos presos são jovens com idade entre 18-24 anos. Quase metade são pardos (43\%) e com ensino fundamental completo (52\%). A grande maioria (78\%) tinha como estado civil, solteiro.

Na Bahia 16,2 mil pessoas estavam sob custódia, apresentando uma taxa de 106,05 custodiados por 100 mil habitantes. Foi a menor taxa do país. Na primeira colocação, o estado Mato Grosso apresentou 834,60 presos a cada 100 mil habitantes. Os homens correspondem por $96 \%$ da população carcerária da Bahia.

A maioria dos casos no estado está em situação sem condenação. Eles correspondem por quase metade do total. Em seguida, presos condenados, mas com execução provisória somam $28,2 \%$ dos casos. Com a execução definitiva, são $21,7 \%$. Apenas $0,02 \%$ são presos civis. A tabela 7 distribui a população carcerária baiana, de acordo com a situação no cadastro do TJ-BA (Tribunal de Justiça da Bahia). As variáveis da tabela 8 são as mesmas utilizadas pelo CNJ, reproduzidas fielmente a partir das referências, neste trabalho. 
Tabela 7 - Destaques dos grupos que compõem o perfil prisional brasileiro

\begin{tabular}{ccc}
\hline Variável & Grupo & \% de destaque \\
\hline Faixa etária & $18-24$ anos & 30,52 \\
Cor & Pardos & 43,62 \\
Estado civil & Solteiro & 78,07 \\
Escolaridade & Fundamental completo & 52,27 \\
\hline
\end{tabular}

Fonte: BNMP/CNJ, 2018.

Tabela 8 - Situação dos presos na Bahia (2018)

\begin{tabular}{ccc}
\hline Natureza da prisão & Quantidade & \% \\
\hline Presos sem Condenação & 8.071 & 49,69 \\
Presos Condenados em Execução Provisória & 4.580 & 28,20 \\
Presos Condenados em Execução Definitiva & 3.529 & 21,72 \\
Internados Provisórios & 26 & 0,16 \\
Internados em Execução Provisória & 16 & 0,10 \\
Internados em Execução Definitiva & 19 & 0,12 \\
Presos Civis & 3 & 0,02 \\
\hline Total & $\mathbf{1 6 . 2 4 4}$ & $\mathbf{1 0 0}$ \\
\hline \hline
\end{tabular}

Fonte: BNMP/CNJ, 2018.

Diante dos quadros delineados, percebe-se que há um crescimento dos homicídios, a expressividade do encarceramento e coloca em questão a efetividades das políticas públicas adotadas até então. De acordo com Cerqueira (2008) um plano emergencial dever colocado em prática para sanar os graves problemas da estrutura do sistema prisional baiano.

O autor ainda chama atenção para a questão policial, segundo ele a política baiana "optou por colocar ênfase no policiamento reativo e muitas vezes brutal nos territórios da periferia, sem que fosse efetivada uma política precedida por planejamento, por prevenção social e pelo investimento em investigação e inteligência policial, que são a base da polícia moderna." (CERQUEIRA, 2018, p.30).

\section{CONSIDERAÇÕES FINAIS}

O avanço da violência no estado da Bahia e em suas cidades polo tem como ponto central a desigualdade social e a concentração de renda. O cenário baiano caracterizado pela violência, propicia a sensação de recolhimento das pessoas a partir do receio de se tornaram vítimas de crimes.

Um outro ponto que pode ser futuramente desenvolvido é a migração de facções, oriundas do Sudeste brasileiro e como ela estaria influenciado nos dados atuais. Este aspecto possui interrelações interessantes na dinâmica do crime: consumo e tráfico de drogas; a rede de comunicação e o "poder" que criminosos importantes ainda possuem no país - mesmo encarcerados; o contraponto entre este fenômeno e as políticas de redução das desigualdades, implementadas desde os anos 2000.

As cidades médias selecionadas neste artigo, reproduzem parte da realidade atribuída à literatura. Embora o Estado adote medidas para minimizar o alto índice de homicídios, o que se percebe é uma baixa efetividade diante dos dados divulgados anualmente pelos institutos que abordam a segurança pública. $\mathrm{O}$ quadro é comum em outras unidades federativas do Nordeste, que estão tendo seus indicadores aumentados em maior velocidade que no restante do território nacional.

Traçar medidas que possam reverter ou minimizar este diagnóstico é uma tarefa complexa, considerando a diversidade das causas que provocam os conflitos. As premissas precisam partir da reflexão sobre os anseios da sociedade quanto as suas demandas, lacunas e contradições. O diálogo entre o poder público e a população é o canal mais apropriado para encontrar os métodos mais eficazes dentro do campo da legalidade.

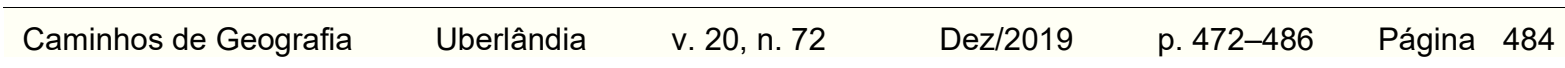




\section{REFERENCIAS}

ARAÚJO, J.P.F.; ANTIGO, M.F. Desemprego e qualificação da mão de obra no Brasil. Revista de Economia Contemporânea. v. 20, n. 2, p. 308-335. 2015. Disponível em: <https://doi.org/10.1590/198055272025>. Acesso em: 09 de novembro de 2018. https://doi.org/10.1590/198055272025

CANO, Ignacio; SANTOS, Nilton. Violência letal, renda e desigualdade social no Brasil. Rio de Janeiro: 7 Letras, 2001.

CARVALHO, B.N; LOBATO, T.C; CARVALHO, A.V; GUIMARÃES, J.LC. Relação da criminalidade com os índices de desemprego: um estudo de caso. Enciclopédia biosfera, Centro Científico Conhecer - Goiânia, v.14 n.25, 2017. Disponível em:

<http://www.conhecer.org.br/enciclop/2017a/soc/relacao.pdf> Acesso em: 16 de novembro de 2018 https://doi.org/10.18677/EnciBio 2017A148

CERQUEIRA, D. R. C. Mapa de homicídios ocultos no Brasil. Brasília: Ipea. 2013 (Texto para Discussão, n. 1848).Disponível em:

$<$ http://www.ipea.gov.br/portal/index.php?option=com_content\&view=article\&id=19232> Acesso em: 01 de outubro de 2019.

CNJ - Conselho Nacional de Justiça. Banco Nacional de Monitoramento de Prisões 2018.

Disponível em:

<http://www.cnj.jus.br/files/conteudo/arquivo/2018/08/57412abdb54eba909b3e1819fc4c3ef4.pdf>.

Acesso em 18 de novembro de 2018.

DEEPASK. Indicadores de mortalidade (2010). Disponível em:

<http://www.deepask.com/goes?page=Municipios-sao-confrontados-pelo-numero-de-homicidio> Acesso em: 30 de outubro de 2018.

GENNARI, Ricardo. Facções criminosas estão migrando para Norte e Nordeste. Radio Senado. Disponível em: <https://www12.senado.leg.br/radio/1/conexao-senado/ricardo-gennari-alerta-sobremigracao-de-faccoes-criminosas-para-norte-e-nordeste> Acesso em: 02 de outubro de 2019.

IBGE - Instituto Brasileiro de Geografia e Estatística. Censo 2010. Disponível em:

$<$ https://cidades.ibge.gov.br/brasil/ba/panorama>. Acesso em: 11 de novembro de 2018.

Cidades em panorama 2016. Disponível em:

<https://cidades.ibge.gov.br/brasil/ba/panorama> Acesso em: 01 de outubro de 2019.

Divisão Urbano Regional do Brasil 2013. Disponível em:

<ftp://geoftp.ibge.gov.br/organizacao_do_territorio/divisao_regional/divisao_urbano_regional/documen tacao/divisao_urbano_regional_apresentacao_do_trabalho.pdf> Acesso em: 18 de novembro de 2018.

IPEA - Instituto de Pesquisa Econômica Aplicada, FBSP - Fórum Brasileiro de Segurança Pública. Atlas da Violência 2018. Disponível em:

<http://www.ipea.gov.br/portal/images/stories/PDFs/relatorio_institucional/180604_atlas_da_violencia 2018.pdf>. Acesso em: 17 de novembro de 2018.

MINISTÉRIO DA ECONOMIA. CAGED - Cadastro Geral de Empregados e Desempregados. Disponível em: <http://pdet.mte.gov.br/caged?view=default> Acesso em: 03 de outubro de 2019.

NORONHA, C.V; MACHADO, E.P; TAPPARELLI, G.; CORDEIRO, T.R; LARANJEIRA, D.H; SANTOS, C.A.T. Violência, etnia e cor: um estudo dos diferenciais na região metropolitana de Salvador, Bahia, Brasil. Revista Panamericana de Salud Publica/ 5(4/5), 1999. Disponível em: <https://scielosp.org/article/rpsp/1999.v5n4-5/268-277/pt/>. Acesso em: 18 de novembro de 2018. https://doi.org/10.1590/S1020-49891999000400010

PEDRAZZINI, Yves. A violência das cidades. Tradução de Giselle Unti. Petrópolis: Vozes, 2006.

PNUD - Programa das Nações Unidas para o Desenvolvimento. Atlas do Desenvolvimento Humano no Brasil (2013). Disponível em: <http://www.atlasbrasil.org.br/2013/> Acesso em: 02 de outubro de 2019 
PINHEIRO, Paulo Sérgio. Violência, crime e sistemas policiais em países de novas democracias. Tempo Social; Rev. Sociol.USP, S. Paulo: 43-52, maio de 1997. https://doi.org/10.1590/S010320701997000100003

SANTOS, Itamar Rocha dos. Aspectos da Violência Urbana. Cadernos de Ciências Sociais Aplicadas. UESB Vitória da Conquista, n. 5/6 p. 237-250, 2009.

SCHABBACH, Letícia Maria. Desigualdade, pobreza e violência metropolitana. IX ENCONTRO DA ABCP. Brasília: 2014. Disponível em:

$<$ https://cienciapolitica.org.br/system/files/documentos/eventos/2017/04/desigualdade-pobreza-eviolencia-metropolitana-740.pdf> Acesso em: 15 de novembro de 2018.

Recebido em: 22/01/2019

Aceito para publicação em: 15/10/2019 